\title{
THE PARAESTHESIAE INDUCED BY COLD
}

\author{
BY \\ JOHN MARSHALL \\ From the Neurological Research Unit of the Medical Research Council, \\ National Hospital, Queen Square, London
}

The paraesthesiae which occur during and after the occlusion of the circulation to a limb have been extensively studied by Bazett and McGlone (1932), Lewis, Pickering, and Rothschild (1931), Zotterman (1933), Kugelberg (1944), Weddell and Sinclair (1947) and Merrington and Nathan (1949). Paraesthesiae induced by subjecting a limb to cold have, however, received but scant attention. Wolf and Hardy (1941) in their studies on pain in a limb induced by cooling observed the occurrence of " pins and needles" when the hand was placed in water below $12^{\circ} \mathrm{C}$., and wrote of the subject being " forced to withdraw his hand owing to the suffering imposed by the growing intensity of the pins and needles sensation ". In similar studies Kellgren, McGowan, and Hughes (1948) noted, besides cold pain, two further sensations which they called skin pain and tingling. Bickford (1939), when cooling peripheral nerves rapidly, observed pain but did not mention other sensations. Sinclair and Hinshaw (1951a) specifically denied the occurrence of any tingling or "touch paraesthesiae" during the development of cold blocks of the ulnar and lateral popliteal nerves. These different accounts may be due in part to the fact that each study was concerned with a particular feature rather than with the whole experience when a limb or a nerve was subject to cooling.

The present study is concerned with establishing what spontaneous, sensory experiences occur when a limb is cooled. It further seeks to locate the site of origin of these subjective phenomena, and the nervous pathways which conduct them to the sensorium. It also endeavours to find the relationship of these phenomena to those produced by ischaemia of a limb. All authors have agreed that pain can be induced by cooling a nerve, and as the features of this cold pain have been extensively studied by Wolf and Hardy, attention here will be mainly devoted to the other phenomena observed.

\section{Experiments}

The observations reported here were made on six healthy subjects. The findings were substantially the same in each one ; the relevant differences will be mentioned in the discussion.

When the hand up to the level of the wrist is placed in water at $4^{\circ} \mathrm{C}$. the first sensation experienced is that of intense cold. After 10 to 15 seconds a dull, diffuse, aching pain is felt in the hand and often in the forearm above the water level, especially along the ulnar border. This aching pain rapidly increases to its maximum severity, and then slowly subsides, ceasing in five to seven minutes. Between one and two minutes after immersion, while the pain is still present, there begins in the hand a very mild, diffuse, tingling sensation felt best in the palmar aspect of the fingers. In quality it is most like ischaemic tingling, but lacks the discrete, irregular feeling of post-ischaemic pricking. It is not affected by moving the fingers, but light pressure on the skin temporarily relieves it. This tingling sensation lasts from three to five minutes though the end-point is difficult to gauge. In addition to the dull pain and the tingling sensation already described, there begins about three minutes after immersion a severe burning or smarting sensation felt diffusely in the skin of the hand. This increases in severity until it becomes uncomfortable. Most subjects consider this to be by far the most unpleasant sensation of the three. It seems only to occur in very cold water of $4^{\circ} \mathrm{C}$. or less, and may last for five or six minutes (Fig. 1). These three are the phenomena that have been observed, namely, cold pain, a tingling sensation, and a burning sensation. These terms will be used to designate them in this paper.

Threshold for Tingling and Burning.-The hand was placed in water at $37^{\circ} \mathrm{C}$. for five minutes and then transferred to water at different temperatures. It appeared that the temperature level at and below which the tingling sensation could be induced was about $15^{\circ} \mathrm{C}$. It varied slightly in different subjects from $13^{\circ} \mathrm{C}$. to $15^{\circ} \mathrm{C}$. but was constant in any one subject. The threshold for the burning sensation was much lower. It was never experienced 


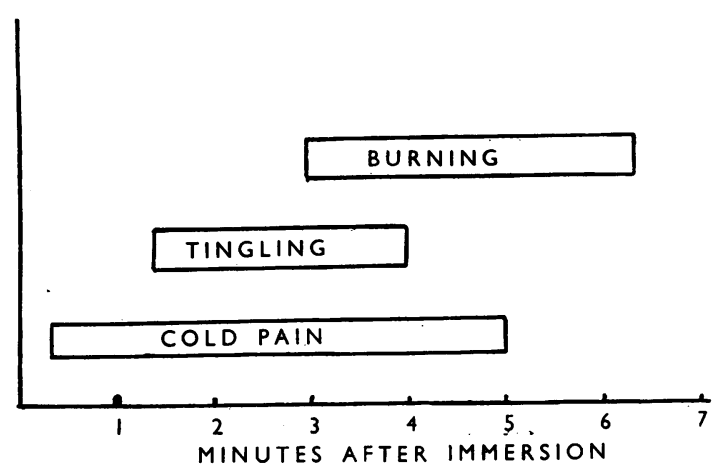

FIG. 1.-Diagram of the onset and duration of paraesthesiae following immersion of the hand in water at $4^{\circ} \mathrm{C}$.

unless the temperature of the water was $4^{\circ} \mathrm{C}$. or lower.

Effect of Range of Temperature Change.-The possibility that the tingling and burning might be dependent on the range of temperature change rather than on the final level reached was next investigated. Placing the hand on separate occasions in water at $37^{\circ} \mathrm{C}$., $22^{\circ} \mathrm{C}$., and $16^{\circ} \mathrm{C}$. for five minutes and then transferring it to water at $10^{\circ} \mathrm{C}$. produced in each instance tingling sensations having the same degree of severity and time of onset. The burning sensation likewise did not appear to be dependent on the range of temperature change. Transferring the hand from water at $37^{\circ} \mathrm{C}$. and $19^{\circ} \mathrm{C}$. to water at $2^{\circ} \mathrm{C}$. produced a burning sensation of like severity and time of onset.

Effect of Rate of Cooling.-Instead of transferring the hand immediately from water at one temperature to water at a lower temperature, the temperature of the water in which the hand was immersed was lowered at the approximate rate of $1^{\circ} \mathrm{C}$. per minute from $18^{\circ} \mathrm{C}$. to $13^{\circ} \mathrm{C}$. Cold pain was not felt, but the tingling sensation appeared at the same temperature level as it had when the temperature was lowered suddenly. Similarly the burning sensation appeared when the temperature reached $4^{\circ} \mathrm{C}$. even with slow cooling. Cold pain, therefore, seems to be dependent to a great extent on the rate of temperature change, whereas tingling and burning depend more on the actual temperature reached.

Severity of Tingling and Burning in Relation to Temperature.-Though the temperature thresholds at which the tingling and burning sensations appeared were constant, the lower the temperature the more severe was the tingling or burning. Thus with the right hand in water at $10^{\circ} \mathrm{C}$. and the left in water at $1^{\circ} \mathrm{C}$. more severe tingling was experienced in the left hand. Over the range of $15^{\circ} \mathrm{C}$. to $0^{\circ} \mathrm{C}$. used in these experiments the lower the temperature the more severe the tingling and the longer its duration. The short range from $4^{\circ} \mathrm{C}$. to $0^{\circ} \mathrm{C}$. made observation of a difference in the degree of burning more difficult but it did seem that the sensation was more severe at $0^{\circ} \mathrm{C}$. than at $4^{\circ} \mathrm{C}$.

Effect of Further Lowering Temperature after Cessation of Tingling.-With the hand in water at $10^{\circ} \mathrm{C}$. the tingling sensation appeared as usual. Three minutes after all tingling had ceased the hand was transferred to water at $4^{\circ} \mathrm{C}$. Tingling was again experienced, beginning at one minute 45 seconds after immersion, and was still present when it was obscured by the severity of the burning which began at two minutes 50 seconds.

Effect of Removing Hand from Cold for a Period.After being in water at $37^{\circ} \mathrm{C}$. for five minutes the hand was transferred to water at $12^{\circ} \mathrm{C}$., whereupon the usual tingling appeared. After five minutes, when all tingling had ceased, the hand was returned to $37^{\circ} \mathrm{C}$. for two minutes, and then re-immersed at $12^{\circ} \mathrm{C}$. On this occasion neither tingling nor cold pain was felt. The experiment was repeated but this time the hand was left at $37^{\circ} \mathrm{C}$. for three minutes. When it was re-immersed in water at $12^{\circ} \mathrm{C}$. cold pain developed followed by the tingling sensation. When the hand after preliminary cooling was immersed in water at $16^{\circ} \mathrm{C}$. it required five minutes at this temperature before re-immersion in cold water produced tingling again. It seems, therefore, that the changes in the nerve' which permit the redevelopment of the paraesthesiae on further cooling proceed more rapidly at a higher temperature.

The period above threshold required for the burning sensation to recur on cooling the hand again was similar. Thus, after being in water at $1^{\circ} \mathrm{C}$., a period of at least five minutes at $18^{\circ} \mathrm{C}$. was required before re-immersion at $1^{\circ} \mathrm{C}$. was followed by a recurrence of the burning.

Site of Origin of Paraesthesiae.-It was found that immersing one finger only on the right and the whole hand on the left in water at $3^{\circ} \mathrm{C}$. produced tingling and burning of equal intensity on both sides. In the case of the right hand the sensations were felt only in the immersed finger, while on the left side they were experienced diffusely in the whole hand. Thus, though the intensity of the sensations seemed the same in comparable areas on the two sides, the greater area of burning on the left made the total discomfort greater on that side. When the limb as far as the elbow was immersed in water at $3^{\circ} \mathrm{C}$. tingling and burning occurred, but were con- 
fined to the hand. Nothing but a cold sensation and cold pain were felt in the forearm.

In the next experiment ice was placed around the groove at the elbow in which lies the ulnar nerve, the forearm and hand being in a room temperature of $21^{\circ} \mathrm{C}$. The tingling sensation developed, but was felt only in the little and ring fingers and the ulnar border of the hand. Cold pain also appeared, but was felt around the immersed elbow and down the ulnar border of the forearm. No cold pain was felt in the hand. The burning sensation was not felt at all, neither in the elbow, hand, nor fingers.

A further step was to place the hand in $8 \%$ celloidin in equal parts of ether and alcohol (Merrington and Nathan, 1949). As this dries there develops an intense pallor of the skin, and on removing the celloidin a typical post-ischaemic hyperaemia appears. The assumption was made that this ischaemia would render the sensory endorgans functionless. Ten minutes after a celloidin coat was thus applied the hand was immersed in water at $2^{\circ} \mathrm{C}$. whereupon cold pain, tingling, and burning all developed as usual. From these experiments it is concluded that cold pain and tingling arise in the nerve trunks. The burning sensation, however, appears to arise more peripherally.

Relation to Ischaemic Paraesthesiae.-The possibility that the tingling sensation was a mild form of ischaemic paraesthesiae induced by the vasoconstriction caused by the cold was investigated. A sphygmomanometer cuff was placed on the arm above the elbow and inflated to $200 \mathrm{~mm}$. of mercury. Ischaemic paraesthesiae developed as usual, and when they had entirely ceased the hand was placed in water at $5^{\circ} \mathrm{C}$. The tingling sensation developed in the same manner as when the circulation was not occluded. This indicates that the tingling sensation due to cold may occur after the paraesthesiae due to the development of ischaemia have ceased.

Sensory Fibres Involved in the Sensations.-A cuff was placed on the arm and inflated to $200 \mathrm{~mm}$. of mercury, the forearm and hand being immersed in water at $37^{\circ} \mathrm{C}$. Twenty minutes after occlusion touch sensibility in the hand was lost even to a nylon thread of $70 \mathrm{~g}$. tension. The threshold for pain as aroused by pinprick was at this stage unchanged. The hand was then transferred to water at $3^{\circ} \mathrm{C}$. Cold pain and the burning sensation developed, but no tingling was felt. This failure to arouse tingling at this temperature strongly suggests that this form of paraesthesiae is dependent upon the integrity of the fibres which subserve touch sensibility, this being the only form of sensation lost at this stage.

In the next experiment a cuff was placed on the arm and inflated to $200 \mathrm{~mm}$. of mercury but left in situ for 45 minutes. At this stage touch sensibility was lost to a nylon thread of $70 \mathrm{~g}$. tension, a thrust with a $140 \mathrm{~g}$. pin produced no pain, a testtube containing water at $60^{\circ} \mathrm{C}$. caused no sensation, but a cube of ice applied to the skin of the fingers produced a burning sensation with no feeling of cold. A test-tube containing water at $4^{\circ} \mathrm{C}$., however, was not felt at all in the fingers. Squeezing the webs of the fingers or the finger tips also produced an extremely unpleasant burning feeling indistinguishable from that produced by ice. When the whole of the fingers was immersed in water at $4^{\circ} \mathrm{C}$. the burning sensation developed to a severe degree of intensity. From this experiment it seemed that the burning sensation was carried by those fibres which carry pain from structures below the skin. The fact that ice, though producing no sensation of cold, was able to give rise to a burning sensation, however, prevented a definite conclusion from being reached.

In an endeavour to produce a greater and earlier loss of cold sensibility a cold block of the ulnar nerve was next induced. The groove containing the left ulnar nerve at the elbow was immersed in a mixture of ice and water at $1^{\circ} \mathrm{C}$., the forearm and hand being in air at $21^{\circ} \mathrm{C}$. Anaesthesia was allowed to develop until ice placed on the little finger produced neither cold nor burning sensations. Water at $55^{\circ} \mathrm{C}$. was still felt as hot, and a $90 \mathrm{~g}$. pin still produced pain. At this stage the little fingers of both hands were immersed in water at $1^{\circ} \mathrm{C}$. The burning sensation developed after about one minute and slowly increased, being of equal intensity on both sides. From this it seemed clear that the burning sensation could be produced in the absence of sensibility to cold.

Pain from structures below the skin is carried by $C$ fibres which have been shown by Gasser and Erlanger (1929) to be the first to be affected in a procaine block. In the next experiment the ulnar nerve at the elbow was infiltrated with $1 \%$ procaine. As soon as the block began to develop the little fingers of both hands were immersed in water at $1^{\circ} \mathrm{C}$. At this stage the sensory state of the little finger on the side of the block was that touch with a nylon thread of $4 \mathrm{~g}$. tension was unchanged as also were cold and warmth. Pain from the skin required a $36 \mathrm{~g}$. pin compared with a $13 \mathrm{~g}$. pin before, and pain from deep tissues could not be aroused even with $20 \mathrm{lb}$. press'ure from an algesio- 
meter. When the little fingers were inserted in the water tingling developed as usual. Cold pain and the burning sensation were, however, not felt at all.

The experiment in which applying a test-tube containing water at $4^{\circ} \mathrm{C}$. to a small area produced no sensation whereas immersing the whole hand was followed by the burning sensation, suggested that the amount of tissue stimulated was an important factor. As the burning sensation is most intense when the limb is cooled while ischaemic, a cuff was placed on the arm, inflated to $200 \mathrm{~mm}$. of mercury and left for 45 minutes. The tip of one finger was then immersed in water at $1^{\circ} \mathrm{C}$. The smarting sensation did not develop until seven seconds after immersion. The finger was removed, the smarting ceased, and then the whole hand was inserted in the water whereupon the smarting developed immediately. This confirmed that the amount of tissue being stimulated was a factor in the development of the smarting.

One further observation was made on a subject who had had the spino-thalamic tract divided on the right side for pain due to secondary carcinoma. On the left foot a $140 \mathrm{~g}$. pin was not felt as pain, and $20 \mathrm{lb}$. pressure with an algesiometer was likewise painless. Ice and a test-tube containing water at $55^{\circ}$ C. were felt merely as touches. The whole of the left foot was inserted in ice and water at $1^{\circ} \mathrm{C}$. but neither cold pain nor burning were felt, the patient continuing to converse quite happily. After five minutes the foot was withdrawn. The right foot was then inserted and immediately cold was felt followed by cold pain and smarting. The patient's face was contorted with anguish and despite the utmost encouragement he withdrew his foot, apologising for not being able to continue the experiment. Since the cordotomy the patient had experienced spontaneous tingling in the left foot, and hence observations on cold tingling were not possible.

\section{Discussion}

It is difficult to correlate the sensations noted in these experiments with those previously reported in the literature. There appears to be general agreement as to the nature and characteristics of cold pain, and as this has been extensively studied by Wolf and Hardy (1941), and Kellgren and others, (1948) it has received little mention here. The observations made in this study confirm that this pain, which is a dull, diffuse ache, develops when the hand is immersed in water about $16^{\circ} \mathrm{C}$. It is felt in the hand and forearm, beginning a few seconds after immersion, and after rising rapidly to a peak at about 60 seconds slowly dies away over a period of four minutes. The lower the temperature of the water the more severe the pain. The temperature change, however, must be sudden, for if the temperature of the water is slowly lowered no pain is felt.

As regards the other sensations, however, the situation is different. Wolf and Hardy mention only one sensation in addition to cold pain, and this they called pins and needles. It began after immersion in water of about $12^{\circ} \mathrm{C}$. ; at lower temperatures the sensation was so unpleasant as to make the subject withdraw the hand from the water. In the present study the tingling sensation, though beginning just above $12^{\circ} \mathrm{C}$., was only of mild degree ; it was certainly never of such an intensity as to make the subject discontinue the experiment. The burning sensation, on the other hand, was, in all subjects except one, extremely severe and unpleasant, and it required considerable perseverance to continue the experiment. Wolf and Hardy also noted that, even after 45 minutes' ischaemia, pins and needles appeared when the hand was placed in cold water. In the present study the tingling sensation was not obtained after touch sensibility from the skin was lost by ischaemia $\Phi^{+}$ The burning sensation, however, persisted undimin $\frac{\mathbb{D}^{+}}{2}$ ished. It seems, therefore, most likely that the ping and needles sensation of Wolf and Hardy is what $\frac{D}{D}$ has been called here the burning sensation, as the accounts of these phenomena have most features if common.

Kellgren and his colleagues observed two sensa tions in addition to deep pain. These they called tingling and skin pain. Their tingling sensation is undoubtedly the tingling sensation of the present study. Their skin pain is almost certainly the burning sensation of this paper. The burning sensation was qualitatively like the burning or smarting described by Lewis and Hess (1933) as occurring with prolonged pain arising from the skin. This likeness may well have led to the application of the term "skin pain".

The other point which must be borne in mind in comparing the reports of different workers is the fact of considerable individual variation in the experience of spontaneous sensory phenomena. Thus, in their studies on post-ischaemic paraesthesiae Merrington and Nathan found marked variations in the individual susceptibility to pricking and tingling, and in the facility with which cooling the limb enhanced the pricking. Likewise Marshall (1952) in a series of cuff tests on healthy subjects found considerable variation from person to person in the ischaemic and post-ischaemic paraesthesiae. Similar variations may well apply to paraesthesiae 
induced by cold. In the present study one subject felt only mild burning. When he put his hand in ice and water at $0^{\circ} \mathrm{C}$. he experienced very severe discomfort, but considered that this was due to severe cold pain, and not to the burning which was present to only a mild degree.

From the experiments described it seems that the cold pain arises in the nerve fibres at the site of cooling. Thus cooling the hand caused pain in the hand radiating up the forearm for some distance, while freezing the ulnar nerve at the elbow produced pain in the elbow radiating down the forearm, but not felt in the hand.

The tingling behaved somewhat differently. Cooling so small an area as one finger produced tingling in that finger, whereas cooling the whole limb from the elbow down produced tingling only in the fingers and hand and not in the forearm. The significant experiment, however, was that when the ulnar nerve at the elbow was cooled tingling was still felt in the little and ring fingers and the ulnar border of the hand. This, combined with the celloidin experiment, makes it clear that the tingling arises in the nerve fibres and not in the sensory end-organs. This accords with the findings of those who have worked on ischaemic paraesthesiae, for here also the tingling, though felt in the fingers and hand, arises at the site of compression of the nerve. But though the site of origin is the same in ischaemic and cold paraesthesiae they differ greatly in intensity. Ischaemic tingling attains a fairly strong degree of intensity, whereas the tingling induced by cold is a mild or moderate phenomenon. This is true even at temperatures which are sufficient to induce loss of sensation much more rapidly than does ischaemia. Further, the tingling sensation induced by cold could be induced after ischaemic tingling had ceased. This suggests, therefore, that, though ischaemic and cold tingling arise at the same site, the mechanism by which they are produced is different. Sinclair and Hinshaw (1951b) have suggested from their observations on the order in which the various sensory modalities are lost during nerve blocks that the effect of cold and ischaemia on nerve fibres may be fundamentally different.

As for the pathways by which the tingling sensation is carried the cuff experiment showed that the tingling sensation induced by cold could not be obtained when touch sensibility was lost, pain and temperature appreciation still being present in the skin. When a procaine block was induced and pain was lost, while touch to a nylon thread of $4 \mathrm{~g}$. tension was still present, the tingling sensation followed immersion in cold water as usual. This is presumptive evidence that the tingling sensation is carried by the fibres which subserve touch sensibility.

The site of origin of the burning sensation is a more difficult problem. As with tingling, when the whole limb to the elbow was immersed in cold water, the burning which arose was confined to the fingers and hand. When, however, the ulnar nerve was cooled at the elbow no burning was felt anywhere. This suggests that cooling a short length of the nerve trunk alone is inadequate to produce the burning. On the other hand if the assumption that the celloidin coat renders the sensory end-organs in the skin functionless is valid, then that experiment would suggest that the sensory end-organs in the skin are not the site of origin of the burning sensation. Furthermore, combining the results of the experiments using ischaemic and cold blocks, when touch, pin, ice, and water at $60^{\circ} \mathrm{C}$. were no longer able to arouse sensations from the skin, burning immediately followed immersion of the hand in cold water. This suggests that skin sensation is not essential for this paraesthesia to be felt.

The question of the amount of the limb inserted in the water is also important for the burning sensation. In the experiment in which after 45 minutes' ischaemia first the finger tip and then the whole hand were inserted in water $1^{\circ} \mathrm{C}$. the burning developed more rapidly when the whole hand was inserted. From the results of these experiments it seems probable that the burning sensation arises in the tissues deep to the skin.

The nature of the fibres which carry the burning sensation seems fairly clear. Touch, cold, warmth, and pain aroused by pricking the skin could all be abolished, and yet burning was still felt. In the procaine block of the ulnar nerve, however, as soon as pain from the deep tissues was lost neither cold pain nor burning could be elicited. The sum total of these results suggests that the burning sensation arises from the stimulation of the nerve endings which subserve pain from tissues deep to the skin.

In conclusion, therefore, it appears that the application of cold to a limb is able to produce spontaneous sensory phenomena. These differ from those which occur during and after ischaemia and seem to be independent of them.

\section{Summary}

When the limb is immersed in cold water there appear cold pain, a dull, diffuse, aching pain; a tingling sensation, which is a diffuse vibrating feeling; and a burning sensation which is a superficial smarting or burning feeling.

The tingling sensation appears after immersion 
in water at temperatures below $15^{\circ} \mathrm{C}$., arises in the nerve trunk, and is conveyed by the nerve fibres which subserve touch sensibility.

The burning sensation appears only after immersion in water below $4^{\circ} \mathrm{C}$. ; it arises in the nerve endings subserving pain from tissues deep to the skin.

The phenomena induced by cold are separate entities from those which occur with ischaemia.

I wish to thank Dr. E. A. Carmichael and Dr. P. W. Nathan for their advice and encouragement with this work.

\section{REFERENCES}

Bazett, H. C., and McGlone, B. (1932). Arch. Neurol. Psychiat., Chicago, 28, 71.

Bickford, R. G. (1939). Clin. Sci., 4, 159.

Gasser, H. S., and Erlanger, J. (1929). Amer. J. Physiol., 88, 581.

Kellgren, J. H. McGowan, A. J., and Hughes, E. S. R. (1948). Clin. Sci., 7, 13.

Kugelberg, E. (1944). Acta physiol. scand., 8, Suppl. 24.

Lewis, T., and Hess, W. (1933). Clin. Sci., 1, 39.

-, Pickering, G. W., and Rothschild, P. (1931). Heart, 16. 1.

Marshall, J. (1952). Journal of Neurology, Neurosurgery and Psychiatry, 15, 242.

Merrington, W. R., and Nathan, P. W. (1949). Ibid., 12, 1.

Sinclair, D. C., and Hinshaw, J. R. (1951a). Quart. J. exp. Psychol., 3, 49. (1951b). Brain, 74, 318.

Weddell, G., and Sinclair, D. C. (1947). Journal of Neurology, Neurosurgery and Psychiatry, 10, 26.

Wolf, S., and Hardy, J. D. (1941). J. clin. Invest., 20, 521.

Zotterman, Y. (1933). Acta med. scand., 80, 185. 